\title{
Interactional appraisal models for the anger appraisals of threatened self-esteem, other-blame, and frustration
}

\author{
Peter Kuppens and Iven Van Mechelen \\ Katholieke Universiteit Leuven, Leuven, Belgium
}

\begin{abstract}
Starting from the interactional assumption of appraisal theories, the present study aimed to identify situation-specific individual differences and their personality correlates for the anger-relevant appraisals of threat to self-esteem, other-blame, and frustration. Participants engaged in a directed imagery task of descriptions of unpleasant situations after which they reported on the appraisals, and were administered measures of potentially relevant dispositional characteristics. The results demonstrated situation-specific individual differences in threatened selfesteem and other-blame, which showed differential relationships with dispositional variables. Threat to self-esteem was related to an unstable self-esteem, neuroticism, and BIS sensitivity in unpleasant evaluative situations, whereas it was related to feeling lowlily valued by others in non-evaluative situations. Other-blame was found to be related to an unstable self-esteem, BIS sensitivity, and neuroticism when someone else is responsible, whereas it was related to interpersonal distrust and low perceived social esteem when oneself or the circumstances are responsible. Individual differences in frustration were found to generalise across contexts, and were primarily related to BIS sensitivity.
\end{abstract}

Appraisal theory has become the dominant approach to account for the elicitation and differentiation of emotions (Scherer, 2001a). Two main assumptions can be said to underlie this theory: A first, interactional, or transactional (Lazarus, 1991), assumption states that appraisals are the result of an evaluation of the environment as a function of an individual's own values, attitudes and goals. A second, more general psychological assumption states that particular patterns of appraisals are associated with particular emotions (Frijda, 1986; Roseman, 1984; Scherer, 2001b; Smith \& Lazarus, 1993). Based on these two assumptions, the appraisal approach

Correspondence should be addressed to: Peter Kuppens, Department of Psychology, Katholieke Universiteit Leuven, Tiensestraat 102, B-3000 Leuven, Belgium.

E-mail: peter.kuppens@psy.kuleuven.be

The research reported in this paper was supported by Grants GOA/00/02 and GOA/05/04 from the Research Fund of the Katholieke Universiteit Leuven. The first author is a postdoctoral research fellow of the Flemish Fund of Scientific Research.

(C) 2007 Psychology Press, an imprint of the Taylor \& Francis Group, an informa business www.psypress.com/cogemotion

DOI: $10.1080 / 02699930600562193$ 
provides both a general theory of emotion, and an account for the observations that different situations can evoke the same emotion and that individuals can react emotionally differently to the same situation (e.g., Lazarus, 1994; Roseman \& Smith, 2001). Until now, however, most research has focused on describing the (general psychological) relations between appraisals and emotions, whereas research examining the interactional nature of the appraisal process is far less abundant (Ellsworth \& Scherer, 2003; Griner \& Smith, 2000; Smith \& Pope, 1992; van Reekum \& Scherer, 1997). As a result, several major appraisal theorists now call for shifting research efforts towards interactional aspects of appraisal theory (Roseman \& Smith, 2001; van Reekum \& Scherer, 1997). For instance, in a chapter entitled "Towards delivering on the promise of appraisal theory", Smith \& Kirby (2001) stated that "relatively little work has examined the antecedents of the appraisals themselves ... nonetheless, such work is vital" (p. 122).

The aim of the present research is to examine the determinants of three appraisals that are generally seen as central components of anger (although they may be relevant for other emotions as well): threat to self-esteem, otherblame, and frustration (e.g., Fehr, Baldwin, Collins, Patterson, \& Benditt, 1999). Starting from the interactional assumption of appraisal theory, we will consider both situational and person determinants of the appraisals under study. In particular, we aim to identify types of situations in which systematic individual differences in the appraisals under study occur, and to relate such differences to person characteristics that may predispose individuals to experience the appraisals in specific circumstances. Our approach is similar to the rationale behind the interactional appraisal models proposed by Smith \& Pope (1992) for the appraisals of motivational relevance and problem-focused coping potential. We will now discuss an interactional model for each appraisal under study, identifying possibly relevant person and situation characteristics that may play a role in the realisation of the appraisal.

\section{THREAT TO SELF-ESTEEM}

Appraising one's circumstances as threatening to one's self-esteem is seen as an important precursor of anger and aggression (e.g., Baumeister, Smart, \& Boden, 1996; Fehr et al., 1999; Kernis, Grannemann, \& Barclay, 1989; Lazarus, 1991); the expression of anger is then assumed to serve as an attempt to maintain or reinstate one's self-esteem or public image.

Several person characteristics have been advanced in relation to the experience of threatened self-esteem. Self-esteem instability has been associated with a heightened sensitivity to evaluative feedback and an increased concern over one's self-view, which would make unstable self-esteem persons 
particularly sensitive to experiencing threats to their self-esteem (Baumeister et al., 1996; Kernis, Cornell, Sun, Berry, \& Harlow, 1993; Kernis et al., 1989; Waschull \& Kernis, 1996). In addition, repeated experiences of threatened self-esteem may leave an individual with the sense of an unstable sense of selfworth. Similarly, it can be assumed that the broad trait of neuroticism predisposes an individual to experience threats to self-esteem. Defined as emotional instability, the latter trait is closely related to self-esteem aspects (Judge, Erez, Bono, \& Thoresen, 2002) and to a heightened sensitivity to negative information (Derryberry \& Reed, 1994; Larsen \& Ketelaar, 1989). Finally, because threatened self-esteem is linked to the experience of anger, it may be that individual differences in the experience of threatened self-esteem are related to trait-anger.

The experience of threatened self-esteem can further be expected to differ across contexts: In particular, in a recent study, it was found that unpleasant situations that involve negative evaluative information may especially elicit threats to self-esteem (Kuppens, Van Mechelen, Smits, De Boeck, \& Ceulemans, 2006); this finding is also consistent with theorising from several authors (Baumeister et al., 1996; Kernis et al., 1989) as well as previous research findings (Stake, Huff, \& Zand, 1995). Taken together, we expect that individual differences in threatened self-esteem will particularly emerge in unpleasant situations that involve evaluative information, and that such differences are related to self-esteem instability, neuroticism, and trait-anger.

\section{OTHER-BLAME}

Blaming others has been related to the experience of anger under different but related forms. First, attributing hostile intentions to the behaviour of others has been identified as an important antecedent of anger and aggression (Averill, 1982; Dodge, 1993; Orobio de Castro, Veerman, Koops, Bosch, \& Monshouwer, 2002). Second, the perception that one is treated disrespectfully or unfairly is recognised as a common source of anger (see Miller, 2001). Finally, Smith and Lazarus (1993) conceived the notion of other-blame itself as the core relational theme of anger, which has been confirmed in subsequent research (e.g., Bennett, Lowe, \& Honey, 2003; Hazebroek, Howells, \& Day, 2001). Each of the abovementioned notions clearly implies blaming someone else for what has happened - therefore, we will generally refer to them as other-blame.

In terms of person characteristics, negatively valenced interpersonal traits or beliefs may be especially relevant for the appraisal of other-blame. In this respect, it has been argued that interpersonal distrust may be a determinant of hostile attribution and blaming others (Kramer, 1994; Valins \& Nisbett, 1987); a chronic distrust towards others may shape expectations in such a 
way that only negative and hostile acts are expected from others. Also, the belief that one is lowlily valued by others (which we will further refer to as perceived low social esteem - for a related concept, see Murray, Griffin, Rose, \& Bellavia, 2003) may contribute to blaming others; peer rejection and sociometric status have indeed been documented as correlates of hostile attribution (Orobio de Castro et al., 2002). Finally, because other-blame is seen as an important determinant of anger, trait-anger may be related to the experience of this appraisal.

In addition, it has been argued that individual differences in other-blame may be context-specific. For instance, prior research suggests that individual differences in other-blame are most prominent in situations that are ambiguous with respect to the role of the other person (e.g., Dill, Anderson, Anderson, \& Deuser, 1997; Hazebroek et al., 2001; Trachtenberg \& Viken, 1994). Taken together, we will examine in which types of situation individual differences in other-blame particularly emerge. Based on prior research, we expect that such differences may particularly be observed in ambiguous situations, and that they are related to negatively valenced interpersonal dispositions as outlined above. As an aside, one may note that our appraisal model for other-blame bears resemblance to hypotheses on the role of hostile attribution in aggression, in which individual differences regarding hostile attribution in ambiguous situations are related to trait levels of aggression (for an overview, see Orobio de Castro et al., 2002).

\section{FRUSTRATION}

Frustration can be defined as the blockage of goal attainment (Anderson \& Bushman, 2002) or the blocking of a goal-directed behaviour sequence (Scherer, 2001b). As such, it is represented in most, if not all, accounts of anger (for an overview, see Kuppens, Van Mechelen, Smits, \& De Boeck, 2003), although it must be noted that the term frustration is sometimes also used to refer to a low-level emotional state itself (e.g., Roseman, Spindel, \& Jose, 1990). In either case, frustration is considered a central component of anger (e.g., Averill, 1982; Berkowitz, 1989; Dollard, Doob, Miller, Mowrer, \& Sears; 1939; Fehr et al., 1999).

In general, the appraisal of goal-blocking or frustration is considered to distinguish between emotions of a positive and a negative valence: Events that are appraised as goal-congruent elicit positive emotions, whereas events that are appraised as goal-incongruent or frustrating elicit negative emotions (Frijda, 1986; Roseman, 1984; Smith \& Lazarus, 1993). A fundamental person variable that is assumed to underlie the negative affective component of anger and other negative emotions is the behavioural inhibition system (BIS). Indeed, BIS activity is thought to be related to a heightened sensitivity 
to negatively valenced stimuli (Carver \& White, 1994). In addition, recent research show that BIS is related to the experience of anger (Harmon-Jones, 2003; Smits \& Kuppens, 2005). As such, we expect that BIS may facilitate frustration appraisals. Because frustration is seen as an important elicitor of anger, it may further be expected that trait-anger is related to the experience of this appraisal as well.

In addition, it may be expected that the experience of frustration is related to goal-importance. Moreover, this may vary across contexts: Frustration may be related to the importance that an individual attaches to a particular goal, albeit only in situations that are relevant for that goal. For instance, in situations that are incongruent with an achievement goal (e.g., performing poor in school), primarily persons that consider achievement to be an important goal will more intensely appraise the event as frustrating. This hypothesis is analogous to the appraisal model for motivational relevance as formulated by Smith and Pope (1992). It is further consistent with theorising by Frijda (1986) who considered the match between a person's expectations or goals and the environment as the primordial elicitor of emotion-relevant appraisal (see also, Moors, De Houwer, \& Eelen, 2004), and with hypotheses formulated by van Reekum and Scherer (1997) regarding individual differences that may underlie the appraisal of goal conduciveness. Taken together, we expect that the appraisal of frustration is related to BIS sensitivity and trait-anger. Moreover, we will verify whether individual differences in frustration vary across goal-specific contexts such that frustration is related to specific goal-importance (i.e., achievement and affiliation) in situations relevant for that goal.

\section{OVERVIEW}

The three interactional appraisal models will be tested in an empirical study that involves a directed imagery task (e.g., Roseman, 1984; Smith \& Lazarus, 1993) to assess the degree to which the participants would experience the appraisals under study in various different situations. Additionally, questionnaires measuring the potentially relevant person characteristics were administered. On the basis of these data (context-specific) dimensions of individual differences in the appraisals will be derived, and related to person characteristics.

\section{METHOD}

\section{Participants}

Participants were 124 university students enrolled in the first year of the psychology educational programme. Participation was a partial fulfilment of 
course credits. The mean age of the participants was 18.9 years; 62 of them were men, 62 were women.

\section{Materials}

\section{Directed imagery task: Situational assessment of appraisals}

Situation vignettes. A list of situation descriptions was constructed, varying with respect to the potentially relevant situation characteristics. A subset of the vignettes was taken from previous research regarding appraisals of anger (Kuppens et al., 2006); the remaining vignettes were constructed for use in the present study. A summary description of the vignettes can be found in Table 1. Their selection and construction was based on the following three considerations: First, given the focus on anger, it was decided to include vignettes that depict unpleasant situations only. Second, the vignettes had to depict situations that could easily be encountered by the participants of the study (i.e., first-year psychology students). Third, in order to evaluate the hypothesised appraisal models, the list had to include situations that varied with respect to the following features: involving evaluative self-relevant information (e.g., vignettes 17,19$)$ or not (e.g., 10, 15); ambiguous with respect to the role or intentions of others (e.g., 9, 24) vs. unambiguous (e.g., 2, 5); blocking of achievement goals (e.g., 13, 16) vs. blocking of affiliative goals (e.g., 12, 18).

Appraisal items. The appraisal of threat to self-esteem was measured by the item: "To what degree do you feel threatened in your self-esteem?" Three items were included to measure other-blame: To what degree "do you feel attacked by someone else?", "do you feel treated disrespectfully by someone else?", and "do you blame someone else for what has happened?" Frustration was assessed by the item: "To what degree do you find the situation frustrating?" Each item had to be rated on a 7-point scale (ranging from $1=$ not at all to $7=$ very strong).

\section{Person characteristics}

Characteristics potentially relevant for threat to self-esteem. The Rosenberg Stability of Self-scale (Rosenberg, 1989) was used to measure stability of self-esteem. The scale consists of five items such as: "Do you ever find that on one day you have one opinion of yourself and on another day you have a different opinion?", which have to be rated on a 4-point scale (ranging from $1=$ not at all to $4=$ very strong). This measure has been used previously as an alternative to a statistical measure of self-esteem stability based on repeated self-esteem assessments (e.g., Roberts, Shapiro, \& Gamble, 1999). In the present study, the reliability as measured by Cronbach alpha equalled .57 . 
TABLE 1

Summary descriptions of vignettes used in directed imagery task and component loadings of situations from three PCA analyses on otherblame, threat to self-esteem, and frustration scores, respectively

\begin{tabular}{|c|c|c|c|c|c|}
\hline \multirow[b]{2}{*}{ Summary situation description } & \multicolumn{2}{|c|}{ Threatened self-esteem } & \multicolumn{2}{|c|}{ Other-blame } & \multirow{2}{*}{ Frustration } \\
\hline & Component 1 & Component 2 & Component 1 & Component 2 & \\
\hline 1. Your friend is in a coma after an accident. & .48 & .03 & .48 & .13 & .47 \\
\hline $\begin{array}{l}\text { 2. A friend lets you down on a date, and calls you the following day to let } \\
\text { you know that he/she didn't feel like meeting with you and went out with } \\
\text { other people instead. }\end{array}$ & -.04 & .75 & .77 & -.12 & .68 \\
\hline $\begin{array}{l}\text { 3. A friend returns your CD player, claiming that everything is } \mathrm{OK} \text {, but it } \\
\text { turns out to be broken afterwards. }\end{array}$ & .60 & .31 & .72 & .18 & .63 \\
\hline 4. A swimming appointment is cancelled because one of your friends falls ill. & .62 & .12 & .19 & .64 & .49 \\
\hline $\begin{array}{l}\text { 5. The waiter in a restaurant informs you that it may take a while before you } \\
\text { can eat because it is a busy evening. Finally, you are served after } 50 \\
\text { minutes of waiting. }\end{array}$ & .65 & .06 & .33 & .46 & .64 \\
\hline $\begin{array}{l}\text { 6. Upon leaving class, you notice that a police officer is removing your bike } \\
\text { because it was illegally parked. }\end{array}$ & .62 & .18 & .30 & .46 & .69 \\
\hline $\begin{array}{l}\text { 7. You are hit by a car on your way to an important appointment, causing } \\
\text { you to miss the appointment. }\end{array}$ & .80 & .12 & .63 & .31 & .77 \\
\hline $\begin{array}{l}\text { 8. You arrange with a good friend to go out together, and he/she will contact } \\
\text { you to meet each other. You don't hear from him/her. }\end{array}$ & .30 & .72 & .72 & .19 & .76 \\
\hline $\begin{array}{l}\text { 9. On holiday with friends, you arrange that each, in turn, has to carry the } \\
\text { heavy tent gear. One day, the tent gear is missing. }\end{array}$ & .77 & .17 & .46 & .64 & .78 \\
\hline $\begin{array}{l}\text { 10. You are hit on your bike by another biker. He/she apologises, and } \\
\text { proposes to pay back the damage to your bike. }\end{array}$ & .76 & -.05 & .41 & .48 & .48 \\
\hline $\begin{array}{l}\text { 11. You have arranged for a hotel room with sea-view. Upon arrival, you are } \\
\text { given a room without a sea-view. }\end{array}$ & .60 & .28 & .68 & .21 & .62 \\
\hline $\begin{array}{l}\text { 12. You are in love with someone but he/she is more interested in someone } \\
\text { else. }\end{array}$ & -.02 & .70 & .46 & .37 & .69 \\
\hline
\end{tabular}




\begin{tabular}{|c|c|c|c|c|c|}
\hline \multirow[b]{2}{*}{ Summary situation description } & \multicolumn{2}{|c|}{ Threatened self-esteem } & \multicolumn{2}{|c|}{ Other-blame } & \multirow{2}{*}{$\frac{\text { Frustration }}{\text { Component } 1}$} \\
\hline & Component 1 & Component 2 & Component 1 & Component 2 & \\
\hline 13. You didn't study hard enough for an exam, and you fail the exam. & .06 & .50 & .09 & .83 & .67 \\
\hline $\begin{array}{l}\text { 14. Your clock failed to wake you up in the morning and you miss the final } \\
\text { class of a course. }\end{array}$ & .59 & -.06 & -.07 & .69 & .50 \\
\hline $\begin{array}{l}\text { 15. You arrange with your roommates that each in turn has to put out the } \\
\text { garbage. When it someone else's turn, you noticed that he/she didn't clean } \\
\text { up. }\end{array}$ & .67 & .15 & .47 & .56 & .53 \\
\hline $\begin{array}{l}\text { 16. A floppy disk holding an important school assignment is destroyed by } \\
\text { your computer. }\end{array}$ & .64 & .12 & .17 & .58 & .70 \\
\hline 17. You hear that a friend is spreading gossip about you. & .11 & .81 & .83 & -.05 & .81 \\
\hline 18. You miss a popular party because you fall asleep at home. & .65 & -.00 & -.11 & .78 & .68 \\
\hline 19. You are fired from your holiday job. & .22 & .79 & .59 & .09 & .71 \\
\hline $\begin{array}{l}\text { 20. A fellow student fails to return your notes when you need them for } \\
\text { studying. }\end{array}$ & .63 & .46 & .71 & .23 & .64 \\
\hline 21. You bump into someone on the street. & .66 & .27 & .53 & .44 & .50 \\
\hline $\begin{array}{l}\text { 22. You have a group assignment with some fellow students. They don't work } \\
\text { hard, and you all get a bad grade. }\end{array}$ & .63 & .45 & .70 & .20 & .76 \\
\hline $\begin{array}{l}\text { 23. You're out for a drink after a hard day's work, and you have to wait } 30 \\
\text { minutes before you are served. }\end{array}$ & .68 & .30 & .56 & .49 & .76 \\
\hline 24. Your roommates went to the movies without informing you. & .25 & .60 & .56 & .26 & .56 \\
\hline
\end{tabular}

Note: Component loadings higher than .40 are displayed in bold. 
Neuroticism was measured by making use of the neuroticism scale of the Dutch version of the NEO-FFI questionnaire (Hoekstra, Ormel, \& De Fruyt, 1996). The questionnaire consists of 60 items, with sets of 12 items measuring each of the five-factor personality dimensions, among which is neuroticism. The scale consists of 12 items, such as: "I often feel tense and nervous", to be rated on a 5-point scale (ranging from $1=$ strongly disagree to $5=$ strongly agree). Validity and reliability of this questionnaire are extensively described in Hoekstra et al. (1996). In the present study, Cronbach alpha equalled .82 .

Characteristics potentially relevant for other-blame. The Mistrust Scale of the Swedish Universities Scales of Personality (SUSP) (Gustavsson, Bergman, Edman, Ekselius, von Knorring, \& Linder, 2000), reflecting suspicion and distrust of other people's motives, was used as a measure of interpersonal distrust. The scale includes seven items such as: "I find it hard to trust other people", which have to be rated on a 4-point scale (ranging from $1=$ not at all applicable to $4=$ totally applicable). Reliability and validity are described in Gustavsson et al. (2000). In our study, Cronbach alpha equalled .71.

Perceived social esteem refers to the assessment of how one is valued by others (in positive or negative terms). As such, it can be considered as the perceived social counterpart of generalised self-esteem (how an individual values him- or herself, in positive or negative terms). Following on this line of thought, we adapted the items from the Rosenberg Self-esteem Scale (Rosenberg, 1989) to obtain a measure of perceived social esteem (see also, Kuppens, 2005). The Rosenberg Self-esteem Scale consists of five positively and five negatively formulated items that reflect an individual's appraisal of $\mathrm{him} /$ herself, such as: "On the whole, I am satisfied with myself", and "At times I think I am no good at all", etc., which have to be rated on a 4-point scale (ranging from $1=$ strongly disagree to $4=$ strongly agree). We reformulated all ten items of the Self-esteem Scale such that they reflected an individual's perceived evaluation by others (e.g., "On the whole, others are satisfied with me", and "At times others think I am no good at all"). After recoding the negatively formulated items, the average score across the ten items is calculated as a measure of perceived social esteem. This measure has been used in previous research (Kuppens, 2005). In the present study, Cronbach alpha equalled .85 .

Characteristics potentially relevant for frustration. A measure of BIS sensitivity was taken from the BIS/BAS Scales (Carver \& White, 1994). The scale consists of seven items such as: "If I think something unpleasant is about to happen I usually get pretty worked up", which have to be rated on a 4-point scale (ranging from $1=$ very false for me to $4=$ very true for me). 
Reliability and validity of this scale have been described elsewhere (Carver \& White, 1994). In the present study, Cronbach alpha equalled .84.

The importance that the participants attached in general to achievementrelated goals and affiliation-related goals was assessed by single-item measures. Regarding achievement, it was decided to focus on the domain of study, given the sample of university students. The item used was: "To what degree is it important for you that your studies are going well?" Regarding affiliation, we decided to focus on maintaining good relations with others. The item used was: "To what degree is it important for you that you have good relations with others?" Each item had to be rated on a 7 point scale (ranging from $1=$ very unimportant to $7=$ very important).

Trait anger. Trait anger was measured with the Dutch adaptation of the Spielberger Trait Anger Scale (van der Ploeg, Defares, \& Spielberger, 1982). The scale consists of 10 items, such as: "I have a fiery temper", which have to be rated on a 4-point scale (from $1=$ almost never to $4=$ almost always). Detailed information on reliability and validity can be found in van der Ploeg et al. (1982). In the present study, Cronbach alpha equalled .86.

\section{Procedure}

The participants received a booklet containing the instructions and tasks. On the first page, the participants were told that the booklet contained a list of situation descriptions. They were encouraged to read each description attentively, and imagine as vividly as possible how they would feel, what they would think, and what they would do in such a situation. After each situation description, they were presented with the appraisal items. Following this directed imagery task, the participants filled out the questionnaires measuring self-esteem instability, perceived social esteem, goal importance, and trait-anger. The data regarding interpersonal distrust, neuroticism, and BIS were collected in an administration of the NEO-FFI, SUSP, and BIS/ BAS scales to the same group of participants a few months prior to the directed imagery task. The participants were guaranteed an anonymous processing of their results.

\section{RESULTS}

As mentioned above, our aim is to identify in which type(s) of situations systematic individual differences in each appraisal occur, and to identify personality correlates of such differences. To this end, we followed a stepwise analytical strategy, conducted for each appraisal separately. First, for each appraisal, a PCA was performed on the appraisal ratings in the different 
situations. This analysis identifies the type(s) of situations in which systematic individual differences with respect to the appraisal occur. The defining characteristics of these situation types can be interpreted from the situation descriptions that load highly on the components obtained via the PCA. Where necessary, to corroborate our interpretation, we additionally collected expert ratings of the situations with respect to the inferred characteristics and examined the relationships between the expert opinions and the component loadings of the situation descriptions. Second, reliable situation-specific individual differences appraisal scores are needed. To this end, for each participant and each component, the average appraisal score across the five situations loading highest on the component was calculated. Aggregation across (a fixed number of) multiple situations ensures a more (and for each aggregation equally) reliable measure compared to using single-item ratings. Moreover, aggregating across a limited set of specific situations ensures a sufficient degree of context-specificity of these scores. Next, the scores were correlated with the dispositional variables hypothesised to be related to the appraisal, reflecting relationships between personality dispositions and individual differences in context-specific appraisal. These correlations were also computed for men and women separately to check for possible gender differences.

\section{Threat to self-esteem}

First, for a PCA performed on the ratings of threat to self-esteem in response to the situation scenarios, a scree test favoured a solution with two components (accounting for $49 \%$ of the total variance). The component loadings of the different situations (after VARIMAX rotation) are reported in Table 1. The loadings range between 0 and .80 , implying that some situations are relevant for individual differences in the appraisal, whereas others are not. The components were interpreted as denoting individual differences in unpleasant situations that involve self-relevant, evaluative information (Component 2) or not (Component 1). In order to corroborate this interpretation, we asked eight experts (researchers in personality and social psychology) to provide ratings of the situations with respect to the degree in which they "contain negative evaluative information for the person in the situation" (rated on a 7-point scale from $1=$ not at all to $7=$ very strong). The interrater agreement was high, $\operatorname{ICC}(2, \mathrm{k})=.85$ (Shrout \& Fleiss, 1979). The average scores across experts of the 24 situations were then correlated with the component loadings of the situations on the two components, yielding values of -.87 (correlation with Component 1) and .76 (correlation with Component 2) (both $p$ s $<.001$ ), clearly supporting our interpretation of the situation components. 
Second, threatened self-esteem scores were averaged per participant separately across the five situations with the highest loadings on Component 1 (Cronbach alpha $=.83$ ), and across the five situations with the highest loading on Component 2 (Cronbach alpha $=.85$ ). The average reported threatened self-esteem equalled $1.47(S D=0.65)$ in non-evaluative situations, and $3.84(S D=1.37)$ in evaluative situations, the difference being significant $(t=20.13, p<.001)$. Next, both average scores were correlated with the dispositional variables. The results are reported in Table 2. From the hypothesised dispositional variables, self-esteem instability and neuroticism were positively related to threatened self-esteem in evaluative situations only (the difference between correlations being significant), whereas trait-anger was related to threatened self-esteem in both evaluative and non-evaluative situations. The same correlations for men and women separately yielded similar results. When examining the relations between threatened self-esteem and the other dispositional variables, threatened self-esteem in evaluative situations showed positive relations primarily with BIS sensitivity, and also with goal importance, whereas negative relations were found between perceived social esteem and threatened self-esteem in both evaluative and non-evaluative situations.

\section{Other-blame}

Three items were used to tap various aspects of other-blame. However, PCA analyses performed on the three items for each situation separately showed the three items to be one-dimensional in each case; moreover, the coefficient

TABLE 2

Correlations between threatened self-esteem in non-evaluative and evaluative unpleasant situations, and personality dispositions

\begin{tabular}{lcc}
\hline & \multicolumn{2}{c}{ Threatened self-esteem } \\
\cline { 2 - 3 } & $\begin{array}{c}\text { Non-evaluative } \\
\text { unpleasant situation }\end{array}$ & $\begin{array}{c}\text { Evaluative } \\
\text { unpleasant situations }\end{array}$ \\
\hline Trait-anger & $.28^{* *}$ & $.40^{* * *}$ \\
Stability self-esteem & $-.11_{\mathrm{a}}^{* *}$ \\
Neuroticism & $.01_{\mathrm{a}}$ & $\left.-.33^{* * *} \mathrm{~b}\right)$ \\
Interpersonal distrust & $.13_{\mathrm{a}}$ & $.37^{* * *} \mathrm{~b}$ \\
Perceived social esteem & $-.23_{\mathrm{a}}^{*}$ & $.09_{\mathrm{a}}$ \\
BIS & $-.07_{\mathrm{a}}$ & $-.26_{\mathrm{a}}^{* *}$ \\
Achievement importance & $-.01_{\mathrm{a}}$ & $.46^{* * *}$ \\
Affiliative importance & $-.09_{\mathrm{a}}^{*}$ & $.28_{\mathrm{b}}^{* *}$ \\
\hline
\end{tabular}

Note: ${ }^{*} p<.05 ;{ }^{* *} p<.01 ;{ }^{* *} p<.001$. Correlations in the same row that do not share subscripts differ at $p<.05$; (b) $p=.07$. 
alpha's for a scale comprising the three items ranged from .54 to .92 (mean alpha $=.76$ ) across the 24 situations. Therefore, it was decided to average the three items to form a compound measure of other-blame.

Next, a PCA was performed on the compound other-blame scores of the 24 situation descriptions. The scree test clearly favoured a solution with two components (accounting for $48 \%$ of the total variance). The component loadings of the different situations (after VARIMAX rotation) are reported in Table 1, and again range from almost zero to highly positive for each component. The first component was interpreted as denoting situations in which someone else is responsible for what has happened (regardless of blame), whereas the second component denoted situations in which oneself or the circumstances are responsible. This interpretation was confirmed by expert ratings: Eight experts provided ratings of the situations with respect to the degree to which "someone else was responsible in the situation" (on a 7 -point scale). The interrater agreement was high, $\operatorname{ICC}(2, \mathrm{k})=.96$. The correlation between the average expert ratings and the component loadings of the situations equalled .83 (component 1) and -.63 (component 2) (both $p s<.001$ ), supporting our interpretation of the situation components.

Second, we averaged the other-blame scores of each participant across the five situations loading highest on each component to obtain scores of otherblame when someone else is responsible (Cronbach alpha $=.80)$ and when oneself or the circumstances are responsible (Cronbach alpha $=.84$ ), respectively. The average reported other-blame in the two situation types equalled $4.61(S D=1.07)$ and $1.54(S D=0.53)$, respectively, the difference being significant $(t=32.88, p<.001)$. Next, both other-blame scores were correlated with the potentially relevant dispositional variables (see Table 3).

TABLE 3

Correlations between other-blame in situations in which someone else and in which self/circumstances are responsible, and personality dispositions

\begin{tabular}{lcc}
\hline & \multicolumn{2}{c}{ Other-blame } \\
\cline { 2 - 3 } & Someone else responsible & Selflcircumstances responsible \\
\hline Trait-anger & $.43^{* * *}$ & $.35^{* * *}$ \\
Stability self-esteem & $-.21_{\mathrm{a}}^{*}$ & $-.08_{\mathrm{a}}$ \\
Neuroticism & $.26_{\mathrm{a}}^{*}$ & $-.04_{\mathrm{b}}$ \\
Interpersonal distrust & $.09_{\mathrm{a}}$ & $.28_{\mathrm{a}}^{* *}$ \\
Perceived social esteem & $-.14_{\mathrm{a}}$ & $-.29_{\mathrm{a}}^{* *}$ \\
BIS & $.37^{* * *}$ & $-.01_{\mathrm{b}}$ \\
Achievement importance & $.20_{\mathrm{a}}^{*}$ & $.03_{\mathrm{a}}$ \\
Affiliative importance & $.23_{\mathrm{a}}^{*}$ & $-.10_{\mathrm{b}}$ \\
\hline
\end{tabular}

Note: ${ }^{*} p<.05 ;{ }^{* *} p<.01 ;{ }^{* *} p<.001$. Correlations in the same row that do not share subscripts differ at $p<.05$. 
The results show that other-blame is related to high interpersonal distrust and low perceived social esteem, yet only in situations in which oneself or the circumstances are responsible (although the differences between correlations are not significant). Trait-anger, in turn, is positively related to other-blame in both types of situation. Again, similar results were obtained for men and women separately. From the other dispositional variables, other-blame when someone else is responsible was positively related to neuroticism, BIS, and goal importance, and negatively to self-esteem instability.

\section{Frustration}

First, for a PCA on the frustration ratings in the 24 situations, a scree test favoured a one-component solution (accounting for $43 \%$ of the variance) all situations loaded higher than .40 on this component (see Table 1). This implies that there is a single major dimension of individual differences in frustration, which plays a role in all included situations. Second, we computed per participant the average frustration score across the five situations loading highest on the component (Cronbach alpha $=.87$ ). The mean frustration score was $5.03(S D=1.05)$. Subsequently, the average frustration score was correlated across participants with the dispositional variables. The correlations across all participants are reported in Table 4. Experienced frustration was strongly related to BIS sensitivity and traitanger, and was moderately related to the importance one attaches to both achievement and affiliative goals. The direction of the correlations were similar for men and women, but differed somewhat in magnitude: For men, frustration was predominantly associated with BIS $(r=.37, p<.01)$ and trait-anger $(r=.45, p<.001)$, and positively but not significantly associated with the goal-importance measures $(r=.19$ and $.16, p>.05$, for achievement and affiliation, respectively); for women, frustration was mainly associated

TABLE 4

Correlation between frustration and personality dispositions

\begin{tabular}{lc}
\hline & Frustration \\
\hline Trait-anger & $.39^{* *}$ \\
Stability self-esteem & $-.23^{*}$ \\
Neuroticism & .19 \\
Interpersonal distrust & .08 \\
Perceived social esteem & .05 \\
BIS & $.48^{* *}$ \\
Achievement importance & $.28^{* *}$ \\
Affiliative importance & $.28^{* *}$ \\
\hline
\end{tabular}

Note: ${ }^{*} p<.05 ;{ }^{* *} p<.01 ;{ }^{* *} p<.001$. 
with BIS $(r=.52, p<.001)$ and with the importance attached to both achievement and affiliative goals $(r=.32, p<.01$, and $r=.42, p<.001$, respectively), and marginally significant with trait-anger $(r=.23, p<.10)$. Additionally, a negative correlation between self-esteem stability and frustration was observed (which mainly held for men, $r=-.26, p<.05$, as compared with women, $r=-.12, p>.05)$.

\section{DISCUSSION}

The aim of the present study was to examine the determinants of appraisals that are considered to be central to anger. We started from the interactional assumption of appraisal theory that states that an appraisal depends on an evaluation of the environment as a function of the individual's own goals, needs, attitudes, etc. Drawing on this assumption, we examined in which types of situations individual differences in the appraisals particularly occur, and identified person characteristics that may underlie such differences.

First, a consistent finding was that the three appraisals under study were positively related to trait-anger across varying contexts. Anger-proneness thus implies higher tendencies to feel threatened in one's self-esteem, to blame others, and feel frustrated, regardless of the situational context. Because these appraisals are seen as important determinants of anger, such tendencies evidently contribute to a higher tendency to experience anger. In this respect, our findings parallel assumptions and findings in the context of the general aggression model (Anderson \& Bushman, 2002) in which aggressive individuals are hypothesised to be characterised by the chronic availability of aggression-eliciting thoughts and beliefs. Similarly, a chronic availability of anger appraisals is now shown to contribute to anger proneness.

A second general finding of interest was that goal strength, both in terms of achievement and affiliation, seemed to amplify the intensity of the studied appraisals in appraisal-relevant contexts (i.e., threatened self-esteem in evaluative situations, other-blame when someone else is responsible, and frustration in unpleasant situations in general). This finding provides insight into the mechanisms that may underlie the hypothesised relationship between goal strength and emotional intensity (Smith \& Pope, 1992; Kuppens, 2005).

\section{Threat to self-esteem}

The evaluative nature of unpleasant situations was shown to play an important role in the appraisal of threat to self-esteem: First, unpleasant evaluative situations elicited higher levels of threatened self-esteem. Second, 
individual differences in threatened self-esteem differ depending on whether a situations is evaluative or not-greater individual differences were observed in situations that were evaluative in nature. Moreover, in such situations, higher levels of appraised threat to self-esteem were found to be associated with an unstable self-esteem or low perceived social esteem, neuroticism, and BIS sensitivity. Thus, persons with an unstable self-esteem or low social esteem may thus be particularly sensitive to (in terms of being threatened by) situations that involve negative evaluative information, being more easily thrown off their balance when confronted with a negative evaluation of themselves, causing them to feel threatened (see also, Baumeister et al., 1996; Kernis et al., 1989). Also, a heightened sensitivity for negative information, reflected in higher levels of neuroticism and BIS activity, relates to a higher reactivity to the unpleasant evaluative cues present in such situations. In other words, our results suggest that the potential personal threat present in an unpleasant evaluative event is more strongly realised for individuals characterised by more negatively focused and unstable personality traits.

Interestingly, our results also revealed a second, more modest, dimension of individual differences in threatened self-esteem emerging in negative situations that are not evaluative in nature. These individual differences showed up as independent from the dimension linked to evaluative situations, and appeared to be moderately related to trait-anger and low perceived social esteem. Given the nature of the situations linked to this second dimension, individuals scoring high on it seem to suffer from some generalisation tendency that makes them experience threatened self-esteem, even in situations that do not include relevant clues for such a threat. The finding that feeling lowlily valued by others is related to threatened selfesteem in these situations, suggests that low perceived social esteem may enhance such a generalisation tendency.

\section{Other-blame}

The results did not support our expectation that systematic individual differences would be found in ambiguous situations. Alternatively, whether or not someone else is responsible (regardless of whether he or she is to blame) was identified as an important situational feature for other-blame. An evident finding was that levels of other-blame are higher in situations when someone else is responsible for what has happened as compared with situations when oneself or the circumstances are responsible. Less evident, however, was the finding that two separate dimensions of individual differences in blaming someone else exist, linked to situations in which someone else is responsible or not. Although both dimensions were related 
to trait-anger, they showed differential relationships with other personality dispositions. On the one hand, interpersonal distrust and perceived low social esteem were associated with blaming others only when oneself or the circumstances are objectively responsible for the unpleasant event that has happened. Thus, distrust and a low perceived social esteem predispose persons to blame others for what goes wrong when oneself or the circumstances are responsible, thereby increasing the likelihood of an attribution error. It is worthwhile to underscore that the tendency for such errors in individuals with lower perceived social esteem was also found for appraising self-esteem threat in non-evaluative situations. As a consequence, the act of blaming others when no one else is responsible may lead to instances of what is called unreasonable anger (Parkinson, 1999) or displaced aggression (Marcus-Newhall, Pedersen, Carlson, \& Miller, 2000).

On the other hand, individual differences in other-blame when someone else is responsible were related to an unstable self-esteem, neuroticism, and BIS activity. This suggests that individuals characterised by a heightened sensitivity for negative information or negative emotionality more easily turn to blaming responsible others when something goes wrong.

\section{Frustration}

It was found that a single dimension of individual differences underlies frustration across different situations, suggesting the existence of a trait-like frustration appraisal tendency. This result is in line with previous research in which a frustration appraisal tendency was found to reflect the amount of situations in which frustration was experienced (Kuppens et al., 2006). In the present study, the frustration tendency was further found to be strongly related to BIS sensitivity. Given that the appraisal of goal-(in)congruence or frustration is assumed to distinguish between negative and positive emotions, this indicates that the relation between BIS sensitivity and the experience of negative emotions (e.g., Carver \& White, 1994) may be mediated by the tendency to experience the appraisal of frustration.

Contrary to expectations, however, no separate dimensions of individual differences in frustration in achievement-related and affiliation-related situations were obtained. In a separate analysis, we computed frustration scores across five achievement situations and across five affiliative situations (the selection of which was based on expert ratings of the relatedness of the situations with respect to study and social relations): Frustration in achievement situations correlated $.74(p<.001)$ with frustration in affiliation situations. A possible explanation for this finding is that the importance attached to achievement (study) and affiliative (social relations) goals also intercorrelate rather highly $(r=.47, p<.001)$ (taking into account that both 
importance measures were tapped by means of single items). This could perhaps be due to the fact that in daily life (and for the present sample of participants) unpleasant achievement-related situations often have affiliative ramifications as well (e.g., reactions of family and friends when failing an exam or when the failure is also caused by others).

\section{Concluding remarks}

Regarding threat to self-esteem and other-blame, our study revealed socalled synergistic person $\times$ situation interactions that elicit the appraisals under study. An interaction is synergistic when a personality trait amplifies the effect of a situational factor (Schmitt, Eid, \& Maes, 2003). Indeed, our results demonstrated that particular situational features (e.g., evaluative nature, someone else responsible) may give rise to a particular appraisal (i.e., threatened self-esteem, other-blame), particularly for persons who are characterised by certain person dispositions (i.e., unstable self-esteem, BIS sensitivity).

In line with previous theorising, our results further suggest a distinction between knowledge or attributions (as objective situational features) and appraisals (as subjective situational evaluations), reflecting the distinction between "cold" and "hot" cognitions in the elicitation of emotion (Smith, Haynes, Lazarus, \& Pope, 1993; see also Cervone, 2004). As the present results indicate, cold cognitions (evaluative nature of situation, someone else is responsible) should be differentiated from hot cognitions (appraisal of threatened self-esteem, someone else is to blame) in that the former are nonevaluative and fact oriented (thus more objective), whereas the latter are a function of the implications for the individual's well-being (and thus more likely to differ across persons). Our results do underscore, however, that both types of cognitions play a significant role in shaping emotional experience.

A limitation of the present study lies in the reliance on self-reported reactions to hypothetical scenarios instead of to real or ongoing events. A major reason for adopting this methodology was that it allowed us to assess the impact of a wide variety of standardised situational contexts on the occurrence of the appraisals and individual differences therein. Yet, past research has warned that such reports may be vulnerable to self-representational concerns or implicit theories (e.g., Harvey, Christensen, \& McClintock, 1983). Although such influences can not be ruled out, we tried to minimise their impact by explicitly guaranteeing anonymity, by constructing situation descriptions that were directly relevant to the sample of participants, and by taking great care in instructing them to imagine the described situations vividly. An indication for validity of the obtained data can be found in the subtle, context-specific individual differences and correspond- 


\section{4}

ing differential correlates that were obtained, which speaks against an overreliance on generalising heuristics by the participants. Also, in general, this methodology has proven to produce valid information regarding appraisal and emotion, and to be useful in theory construction in these domains of research (Robinson \& Clore, 2001; Schorr, 2001).

To conclude, with the present study, we sought to identify the interactional processes that underlie anger-relevant appraisals (although the studied appraisals may also be relevant for other emotions). As such, with this line of research, we hope to contribute to delivering on the promise of appraisal theory of "explaining individual differences in emotional reactions, as well as how emotional reactions can be highly context sensitive" (Smith \& Kirby, 2001).

Manuscript received 8 March 2004

Revised manuscript received 16 December 2005

Manuscript accepted 9 January 2006

\section{REFERENCES}

Anderson, C. A., \& Bushman, B. J. (2002). Human aggression. Annual Review of Psychology, 53, $27-51$.

Averill, J. R. (1982). Anger and aggression: An essay on emotion. New York: Springer-Verlag.

Baumeister, R. F., Smart, L., \& Boden, J. M. (1996). Relation of threatened egotism to violence and aggression: The dark side of high self-esteem. Psychological Review, 103, 5-33.

Bennett, P., Lowe, R., \& Honey, K. L. (2003). Appraisals, core relational themes, and emotions: A test of the consistency of reporting and their associations. Cognition and Emotion, 17, $511-520$.

Berkowitz, L. (1989). Frustration-aggression hypothesis: Examination and reformulation. Psychological Bulletin, 106, 59-73.

Carver, C. S., \& White, T. L. (1994). Behavioral inhibition, behavioral activation, and affective responses to impending reward and punishment: The BIS/BAS scales. Journal of Personality and Social Psychology, 67, 319-333.

Cervone, D. (2004). The architecture of personality. Psychological Review, 111, 183-204.

Derryberry, D., \& Reed, M. A. (1994). Temperament and attention: Orienting toward and away from positive and negative signals. Journal of Personality and Social Psychology, 66, $1128-$ 1139 .

Dill, K. E., Anderson, C. A., Anderson, K. B., \& Deuser, W. E. (1997). Effects of aggressive personality on social expectations and social perceptions. Journal of Research in Personality, $31,272-292$.

Dodge, K. A. (1993). Social-cognitive mechanisms in the development of conduct disorder and depression. Annual Review of Psychology, 44, 559-584.

Dollard, J., Doob, L., Miller, N., Mowrer, O., \& Sears, R. (1939). Frustration and aggression. New Haven, CT: Yale University Press.

Ellsworth, P. C., \& Scherer, K. R. (2003). Appraisal processes in emotion. In R. J. Davidson, K. R. Scherer, \& H. H. Goldsmith (Eds.), Handbook of affective sciences (pp. 572-595). New York: Oxford University Press. 
Fehr, B., Baldwin, M., Collins, L., Patterson, S., \& Benditt, R. (1999). Anger in close relationships: An interpersonal script analysis. Personality and Social Psychology Bulletin, 25, 299-312.

Frijda, N. H. (1986). The emotions. Cambridge, UK: Cambridge University Press.

Griner, L. A., \& Smith, C. A. (2000). Contributions of motivational orientation to appraisal and emotion. Personality and Social Psychology Bulletin, 26, 727-740.

Gustavsson, J. P., Bergman, H., Edman, G., Ekselius, L., von Knorring, L., \& Linder, J. (2000). Swedish universities Scales of Personality (SSP): Construction, internal consistency and normative data. Acta Psychiatrica Scandinavica, 102, 217-225.

Harmon-Jones, E. (2003). Anger and the behavioral approach system. Personality and Individual Differences, 35, 995-1005.

Harvey, J., Christensen, A., \& McClintock, E. (1983). Research methods. In H. H. Kelley, E. Berscheid, \& A. Christensen (Eds.), Close relationships (pp. 449-485). New York: Freeman.

Hazebroek, J. F., Howells, K., \& Day, A. (2001). Cognitive appraisals associated with high trait anger. Personality and Individual Differences, 30, 31-45.

Hoekstra, H. A., Ormel, J., \& De Fruyt, F. (1996). NEO PI-R, NEO FFI Big Five Persoonlijkheidsvragenlijsten: Handleiding. Lisse, The Netherlands: Swets \& Zeitlinger.

Judge, T. A., Erez, A., Bono, J., \& Thoresen, C. J. (2002). Are measures of self-esteem, neuroticism, locus of control, and generalized self-efficacy indicators of a common core construct? Journal of Personality and Social Psychology, 83, 693-710.

Kernis, M. H., Cornell, D. P., Sun, C., Berry, A., \& Harlow, T. (1993). There's more to selfesteem than whether it is high or low: The importance of stability of self-esteem. Journal of Personality and Social Psychology, 65, 1190-1204.

Kernis, M. H., Grannemann, B. D., \& Barclay, L. C. (1989). Stability and level of self-esteem as predictors of anger arousal and hostility. Journal of Personality and Social Psychology, 56, $1013-1022$.

Kramer, R. M. (1994). The sinister attribution error: Paranoid cognition and collective distrust in organizations. Motivation and Emotion, 18, 199-230.

Kuppens, P. (2005). Interpersonal determinants of trait anger: Low agreeableness, perceived low social esteem, and the amplifying role of the importance attached to social relationships. Personality and Individual Differences, 38, 13-23.

Kuppens, P., Van Mechelen, I., Smits, D. J. M., \& De Boeck, P. (2003). The appraisal basis of anger: Specificity, necessity and sufficiency of components. Emotion, 3, 254-269.

Kuppens, P., Van Mechelen, I., Smits, D. J. M., De Boeck, P., \& Ceulemans, E. (2006). Individual differences in appraisal and emotion: The case of anger. Manuscript submitted for publication.

Larsen, R. J., \& Ketelaar, T. (1989). Extraversion, neuroticism and susceptibility to positive and negative mood induction procedures. Personality and Individual Differences, 10, 1221-1228.

Lazarus, R. S. (1991). Emotion and adaptation. Oxford: Oxford University Press.

Lazarus, R. S. (1994). Individual differences in emotion. In P. Ekman \& R. J. Davidson (Eds.), The nature of emotion: Fundamental questions (pp. 332-336). New York: Oxford University Press.

Marcus-Newhall, A., Pedersen, W. C., Carlson, M., \& Miller, N. (2000). Displaced aggression is alive and well: A meta-analytic review. Journal of Personality and Social Psychology, 78, 670689.

Miller, D. T. (2001). Disrespect and the experience of injustice. Annual Review of Psychology, 52, $527-553$.

Moors, A., De Houwer, J., \& Eelen, P. (2004). Automatic stimulus-goal comparisons: Support from motivational affective priming studies. Cognition and Emotion, 19, 29-54.

Murray, S. L., Griffin, D. W., Rose, P., \& Bellavia, G. M. (2003). Calibrating the sociometer: The relational contingencies of self-esteem. Journal of Personality and Social Psychology, 85, $63-84$. 
Orobio de Castro, B., Veerman, J. W., Koops, W., Bosch, J. D., \& Monshouwer, H. J. (2002). Hostile attribution of intent and aggressive behavior: A meta-analysis. Child Development, 73, 916-934.

Parkinson, B. (1999). Relations and dissociations between appraisal and emotion ratings of reasonable and unreasonable anger and guilt. Cognition and Emotion, 13, 347-385.

Roberts, J. E., Shapiro, A. M., \& Gamble, S. A. (1999). Level and perceived stability of selfesteem prospectively predict depressive symptoms during psychoeducational group treatment. British Journal of Clinical Psychology, 73, 14-21.

Robinson, M. D., \& Clore, G. L. (2001). Simulation, scenarios, and emotional appraisal: Testing the convergence of real and imagined reactions to emotional stimuli. Personality and Social Psychology Bulletin, 27, 1520-1532.

Roseman, I. J. (1984). Cognitive determinants of emotion: A structural theory. In P. Shaver (Ed.), Review of personality and social psychology. Vol. 5: Emotions, relationships, and health (pp. 11-36). Beverly Hills, CA: Sage.

Roseman, I. J., \& Smith, C. A. (2001). Appraisal theory: Overview, assumptions, varieties, controversies. In K. R. Scherer, A. Schorr, \& T. Johnstone (Eds.), Appraisal processes in emotion: Theory, methods, research (pp. 3-19). New York: Oxford University Press.

Roseman, I. J., Spindel, M. S., \& Jose, P. E. (1990). Appraisals of emotion-eliciting events: Testing a theory of discrete emotions. Journal of Personality and Social Psychology, 59, 899915.

Rosenberg, M. (1989). Society and the adolescent self-image (reprint ed.). Middletown, CT: Wesleyan University Press.

Scherer, K. R. (2001a). The nature and study of appraisal: A review of the issues. In K. R. Scherer, A. Schorr, \& T. Johnstone (Eds.), Appraisal processes in emotion: Theory, methods, research (pp. 369-392). New York: Oxford University Press.

Scherer, K. R. (2001b). Appraisal considered as a process of multilevel sequential checking. In K. R. Scherer, A. Schorr, \& T. Johnstone (Eds.), Appraisal processes in emotion: Theory, methods, research (pp. 92-120). New York: Oxford University Press.

Schmitt, M., Eid, M., \& Maes, J. (2003). Synergistic person $\times$ situation interaction in distributive justice behavior. Personality and Social Psychology Bulletin, 29, 141-147.

Schorr, A. (2001). Subjective measurement in appraisal research. In K. R. Scherer, A. Schorr, \& T. Johnstone (Eds.), Appraisal processes in emotion: Theory, methods, research (pp. 331-349). New York: Oxford University Press.

Shrout, P. E., \& Fleiss, J. L. (1979). Intraclass correlations: Uses in assessing rater reliability. Psychological Bulletin, 86, 420-428.

Smith, C. A., Haynes, K. N., Lazarus, R. S., \& Pope, L. K. (1993). In search of the "hot" cognitions: Attributions, appraisals, and their relation to emotion. Journal of Personality and Social Psychology, 65, 916-929.

Smith, C. A., \& Kirby, L. D. (2001). Toward delivering on the promise of appraisal theory. In K. R. Scherer, A. Schorr, \& T. Johnstone (Eds.), Appraisal processes in emotion: Theory, methods, research (pp. 121-140). New York: Oxford University Press.

Smith, C. A., \& Lazarus, R. S. (1993). Appraisal components, core relational themes, and the emotions. Cognition and Emotion, 7, 233-269.

Smith, C. A., \& Pope, L. K. (1992). Appraisal and emotion: The interactional contributions of dispositional and situational factors. In M. S. Clark (Ed.), Review of personality and social psychology. Vol. 14: Emotion and social behavior (pp. 32-62). Newbury Park, CA: Sage.

Smits, D. J. M., \& Kuppens, P. (2005). The relations between anger, coping with anger, and aggression, and the BIS/BAS system. Personality and Individual differences, 39, 783-793.

Stake, J. E., Huff, L., \& Zand, D. (1995). Trait self-esteem, positive and negative events, and event-specific shifts in self-evaluation and affect. Journal of Research in Personality, 29, $223-$ 241. 
Trachtenberg, S., \& Viken, R. J. (1994). Aggressive boys in the classroom: Biased attributions or shared perceptions? Child development, 65, 829-835.

Valins, S., \& Nisbett, R. E. (1987). Attribution processes in the development and treatment of emotional disorders. In E. E. Jones \& D. E. Kanouse (Eds.), Attribution: Perceiving the causes of behavior (pp. 137-150). Hillsdale, NJ: Lawrence Erlbaum Associates, Inc.

Van der Ploeg, H. M., Defares, P. B., \& Spielberger, C. D. (1982). Zelf-analyse vragenlijst [Trait Anger Scale]. Lisse, The Netherlands: Swets \& Zeitlinger.

van Reekum, C. M., \& Scherer, K. R. (1997). Levels of processing in emotion-antecedent appraisal. In G. Matthews (Ed.), Cognitive science perspectives on personality and emotion (pp. 259-300). Amsterdam: Elsevier Science.

Waschull, S. B., \& Kernis, M. H. (1996). Level and stability of self-esteem as predictors of children's intrinsic motivation and reasons for anger. Personality and Social Psychology Bulletin, 22, 4-13. 